\title{
Signaling pathways from membrane lipid rafts to JNK1 activation in reactive nitrogen species-induced non-apoptotic cell death
}

\author{
Y-T Wu' ${ }^{1}$, S Zhang ${ }^{1}$, Y-S Kim², H-L Tan ${ }^{1}$, M Whiteman ${ }^{3}$, C-N Ong ${ }^{1}$, Z-G Liư ${ }^{2}$, H Ichijo ${ }^{4}$ and H-M Shen ${ }^{\star, 1}$
}

At present, the signaling pathways controlling reactive nitrogen species (RNS)-induced non-apoptotic cell death are relatively less understood. In this work, various RNS donors are found to induce caspase-independent non-apoptotic cell death in mouse embryonic fibroblasts (MEF). In search of the molecular mechanisms, we first established the role of c-Jun N-terminal kinase (JNK) in RNS-induced non-apoptotic cell death. RNS readily activate JNK, and the jnk1-I- MEF are resistant to RNS-induced cell death. Moreover, the reconstitution of JNK1 effectively restores the sensitivity to RNS. Next, we identified tumor necrosis factor receptor-associated factor 2 (TRAF2) and apoptosis signal-regulating kinase 1 (ASK1) as the essential upstream molecules for RNS-induced JNK activation and cell death. RNS fail to activate JNK and induce cell death in traf2-I- MEF; and reconstitution of TRAF2 effectively restores the responsiveness of traf2-I- MEF to RNS. Moreover, RNS-induced ASK1 activation is impaired in traf2 $-I-$ cells and overexpression of a mutant ASK1 protein suppresses RNS-induced cell death in wild-type MEF cells. Last, we explored the signaling events upstream of TRAF2 and found that translocation of TRAF2 and JNK1 onto membrane lipid rafts is required for RNS-mediated JNK1 activation and cell death. Taken together, data from our study reveal a novel signaling pathway regulating RNS-induced JNK1 activation and non-apoptotic cell death.

Cell Death and Differentiation (2008) 15, 386-397; doi:10.1038/sj.cdd.4402273; published online 16 November 2007

Reactive nitrogen species (RNS) refer to various nitrogenous products including nitric oxide (NO), peroxynitrite $\left(\mathrm{ONOO}^{-}\right)$ and nitrogen dioxide $\left(\mathrm{NO}_{2}\right)$, which are highly reactive and capable of inducing nitrosative stress and impairing the function of their target molecules, including protein, lipid and DNA. ${ }^{1}$ Among the wide range of bioactivities, one important aspect of RNS is their regulatory roles in cell death. Under different circumstances, RNS are capable of inducing either apoptosis or non-apoptotic cell death in a variety of cells. ${ }^{2}$ It has been well studied that RNS-induced apoptosis is executed via the following two main mechanisms: (i) mitochondria-dependent intrinsic apoptosis pathway and (ii) DNA damage and p53 activation. ${ }^{3}$ In contrast, the signalling pathways controlling RNS-induced non-apoptotic or necrotic cell death are less studied. There is evidence suggesting that RNS impair the respiratory function of mitochondria and ATP production and eventually lead to necrosis. ${ }^{4}$

c-Jun N-terminal kinase (JNK) (also known as stressactivated protein kinase) is an important subgroup of the mitogen-activated protein kinases (MAPK) superfamily. JNK plays a critical role in controlling diverse cellular functions such as cell proliferation, differentiation, and cell death in stimuli and cell-type-dependent manners. ${ }^{5}$ It has been suggested that JNK activation is one of the main cellular events in response to various forms of RNS. ${ }^{6}$ At present, a number of intriguing questions regarding RNS-mediated JNK activation remain to be further investigated. First, the signaling pathway controlling RNS-mediated JNK activation has not been well elucidated. It has been shown that RNS activate JNK through MAPK or extracellular signal-regulated kinase kinase (MEK) kinase 1 (MEKK1), apoptosis signal-regulating kinase (ASK1) and MAPK kinase 4 (MKK4), ${ }^{7}$ without knowing the signaling events upstream of ASK1 or MEKK1. Second, JNK is known to play an important role in RNS-induced apoptosis. ${ }^{8}$ It remains to be determined whether JNK is also involved in RNS-induced non-apoptotic cell death. In this study, we first identified JNK1 as the key effector molecule in RNS-induced caspase-independent non-apoptotic cell death in mouse embryonic fibroblasts (MEF). Next, we demonstrated that RNS-induced JNK1 activation and cell death requires tumor necrosis factor (TNF) receptor-associated factor 2 (TRAF2) and ASK1. Finally, we provided evidence

\footnotetext{
${ }^{1}$ Department of Community, Occupational and Family Medicine, Yong Loo Lin School of Medicine, National University of Singapore, Singapore, Singapore; ${ }^{2} \mathrm{Cell}$ and Cancer Biology Branch, Center for Cancer Research, National Cancer Institute, National Institutes of Health, Bethesda, MD, USA; ${ }^{3}$ Institute of Biomedical and clinical sciences, Peninsula Medical School, Devon, UK and ${ }^{4}$ Laboratory of Cell Signaling, Graduate School of Pharmaceutical Sciences, The University of Tokyo, Tokyo, Japan *Corresponding author: H-M Shen, Department of Community, Occupational and Family Medicine, Yong Loo Lin School of Medicine, National University of Singapore, MD3, 16 Medical Drive, Singapore 117597, Singapore. Tel: +65 6516 4998; Fax: + 656779 1489; E-mail: cofshm@ @us.edu.sg

Keywords: RNS; Lipid rafts; TRAF2; ASK1; JNK1; non-apoptotic cell death

Abbreviations: ActD, Actinomycin D; ASK1, apoptosis signal-regulating kinase 1; JNK, c-Jun N-terminal kinase; LDH, lactate dehydrogenase; MAPK, mitogenactivated protein kinase; MEK, mitogen-activated protein kinase or extracellular signal-regulated kinase kinase; MKK, mitogen-activated protein kinase kinase; MTT, 3 [4,5-dimethylthiazol-2-yl]-2,5-diphenyltetrazolium bromide; $\mathrm{M} \beta \mathrm{CD}$, methyl- $\beta$-cyclodextrin; NO, nitric oxide; PARP, poly(ADP-ribose) polymerase; RIP, receptor interacting protein; RNS, reactive nitrogen species; SIN-1, 3-morpholynosidenonimine hydrochloride; SNAP, $( \pm$ )-S-nitroso- $N$-acetylpenicillamine; SNP, sodium nitroprusside; SP, SP 600125; TNF $\alpha$, tumor necrosis factor $\alpha$; TPA, 12-O-tetradecanoylphorbol 13-acetate; TRAF2, TNF receptor-associated factor 2; TNFR1, TNF receptor 1; Z-VAD-fmk, Z-Val-Ala-Asp(OCH3)-Fluoromethylketone.

Received 15.5.07; revised 17.9.07; accepted 25.9.07; Edited by JA Cidlowski; published online 16.11.07
} 
that translocation of TRAF2 and JNK to membrane lipid raft is required for RNS-mediated JNK1 activation and cell death. Taken together, data from our study reveal a novel signaling pathway controlling RNS-induced JNK activation and nonapoptotic cell death.

\section{Results}

RNS induce caspase-independent non-apoptotic cell death in MEF. RNS have been reported to induce cell death, including both apoptosis and necrosis, depending on the intensity of stimulation and the cell type tested. ${ }^{2}$ In this study, two NO donors (sodium nitroprusside (SNP) and ( \pm )$S$-nitroso- $N$-acetylpenicillamine (SNAP)) and one ONOOdonor (3-morpholynosidenonimine hydrochloride (SIN-1)) were used to treat the wild-type mouse embryonic fibroblasts (WT MEF). As shown in Figure 1a and b, all the three different RNS donors induce cell death dosedependently, as measured by either morphological changes or the cell viability test. To determine the form of cell death induced by RNS, we systematically compared the morphological and biochemical features of RNS-induced cell death with that of the typical apoptosis induced by TNF $\alpha$ plus Actinomycin D (ActD). It was found that SNP induced evident membrane disruption at the early stage of cell death

a

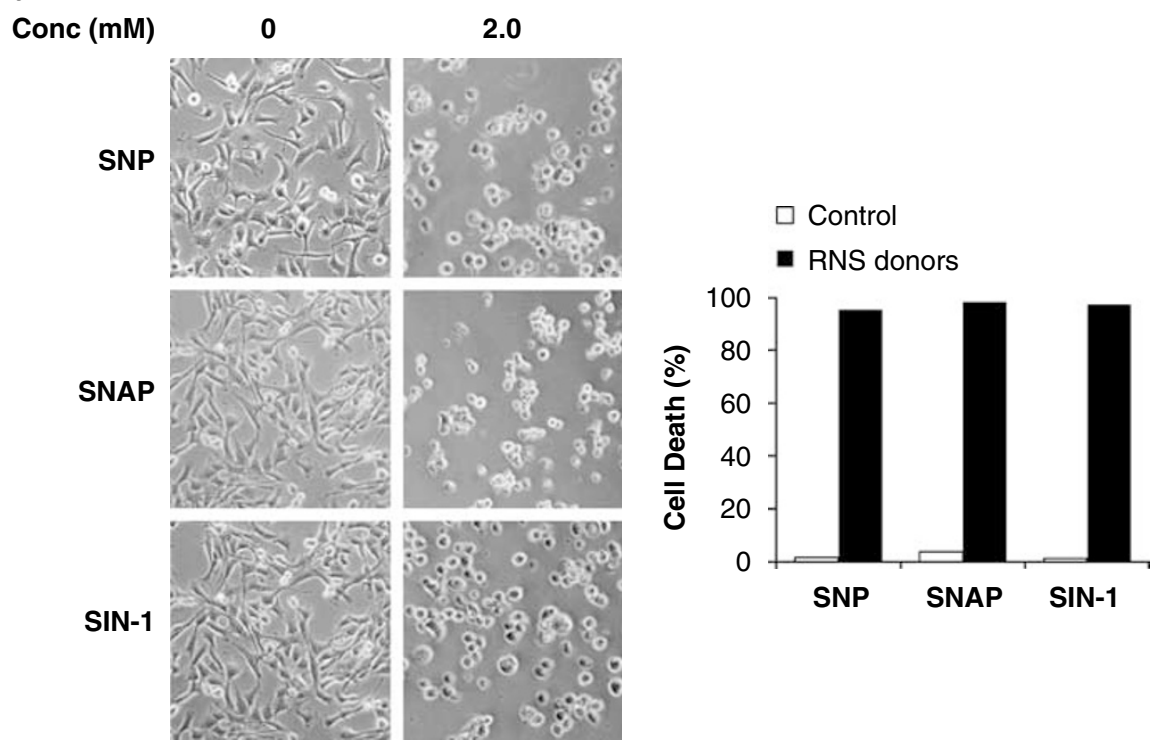

b

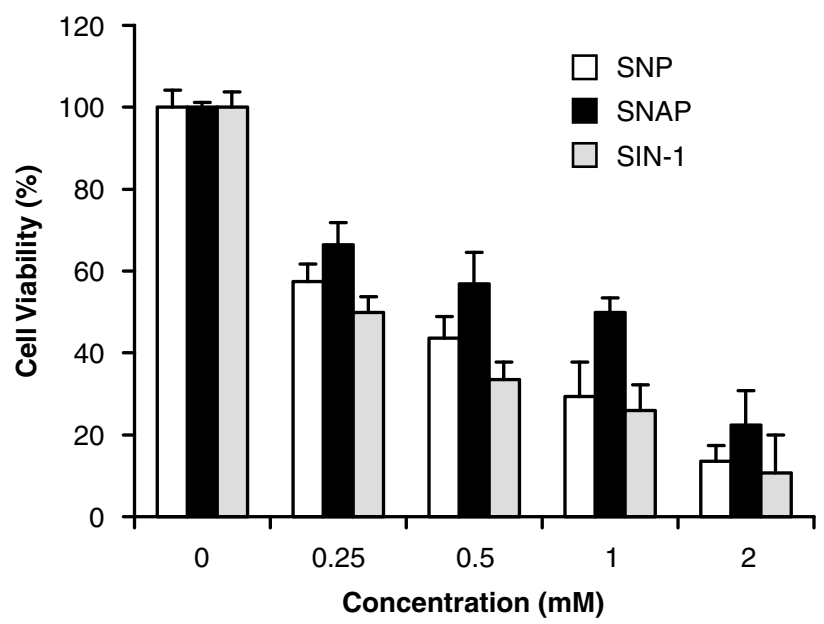

Figure 1 RNS induce caspase-independent non-apoptotic cell death in MEF. (a) Cell death induced by various RNS donors in WT MEF. WT MEF cells were treated with $2 \mathrm{mM}$ SNP, SNAP or SIN- 1 for $12 \mathrm{~h}$. Representative images were taken by a phase-contrast microscope $(\times 200)$. The right panel shows the quantification of cell death based on the percentage of rounded cells in total of 200 randomly selected cells. (b) RNS donors-induced cell death dose-dependently. MEF were treated with various RNS donors for $12 \mathrm{~h}$ and the relative cell viability was quantified using MTT test. (c) SNP-induced cell death evaluated using Sytox-Hoechst-staining. WT MEF cells were treated with SNP $(0.5$ and $1.0 \mathrm{mM})$ for $6 \mathrm{~h}$. ActD $(5 \mu \mathrm{g} / \mathrm{ml})$ plus TNF $\alpha(10 \mathrm{ng} / \mathrm{ml} \times 6 \mathrm{~h})$ was used as the positive control to induce typical apoptosis. (d) Absence of caspase 3 and PARP cleavage in SNP-treated cells. WT MEF cells were treated with SNP as indicated. In one group, cells were pretreated with Z-VAD-fmk $(20 \mu \mathrm{M} \times 1 \mathrm{~h})$, followed by ActD + TNF $\alpha$ for $6 \mathrm{~h}$. Cleavage of caspase 3 and PARP was determined using Western blot. (e) RNS-induced cell death not affected by Z-VAD-fmk. WT MEF cells were treated with SNP for $12 \mathrm{~h}$ with/without pretreatment of Z-VAD-fmk $(50 \mu \mathrm{M} \times 1 \mathrm{~h})$. The cell viability was measured by MTT test. Data in (b) and (e) were presented as mean \pm S.D. from at least three independent experiments 
c

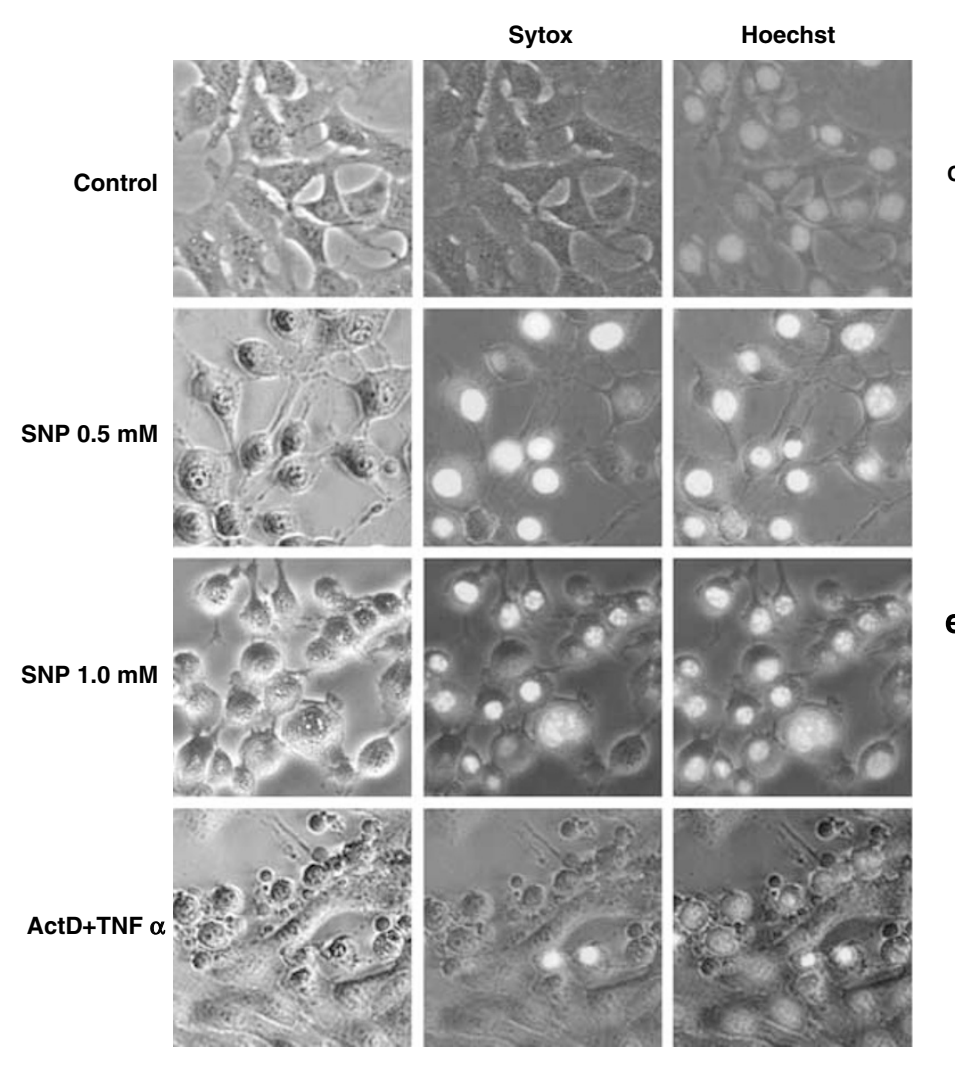

d

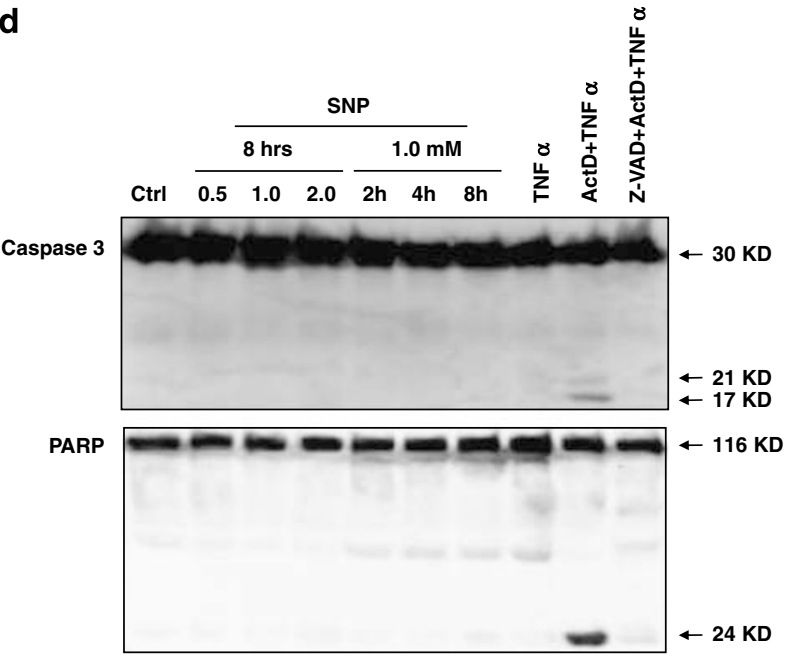

e

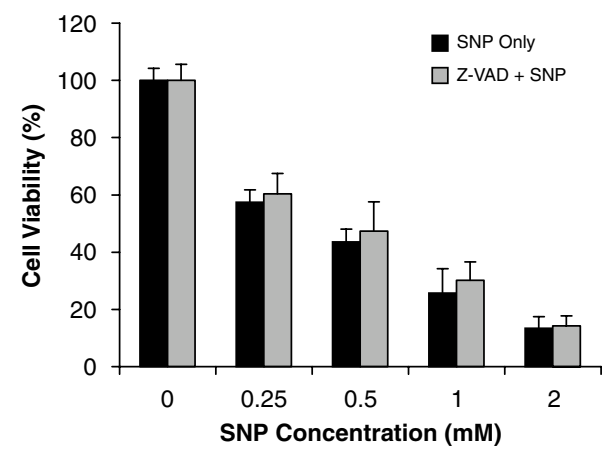

Figure 1 Continued.

indicated by Sytox staining (Figure 1c), without obvious membrane blebs and nuclear condensation indicated by Hoechst staining (Figure 1c). In contrast to typical apoptosis induced by ActD plus TNF $\alpha$, no caspase- 3 and poly(ADPribose) polymerase (PARP) cleavage was found in SNPtreated cells (Figure 1d). Moreover, SNP-induced cell death is not affected by pretreatment of Z-Val-Ala-Asp(OCH3)Fluoromethylketone (Z-VAD-fmk) (Figure 1e), a general caspase inhibitor, which was proved to be able to abrogate caspase 3 and PARP cleavage in apoptotic MEF cells treated with ActD plus TNF $\alpha$ (Figure 1d). Similar results were observed in cell treated with SNAP and SIN-1 (data not shown). It is thus believed that RNS mainly induced nonapoptotic cell death independent of the caspase cascade.

JNK1 plays a critical role in RNS-induced non-apoptotic cell death. JNK has been well established as the key modulator for various stress responses, including nitrosative stress. ${ }^{9}$ Although JNK is known to play an important role in RNS-induced apoptosis, ${ }^{8,10}$ it remains to be determined whether JNK is also involved in RNS-induced non-apoptotic cell death. In this study, we first observed a relatively slow but sustained JNK activation after SNP treatment: evident JNK activation started from $2 \mathrm{~h}$ and reached the peak at $4 \mathrm{~h}$ (Figure 2a). Sustained JNK activation was observed up to $9 \mathrm{~h}$ after treatment (data not shown). SP 600125 (SP), a specific general JNK inhibitor, is able to suppress SNP-induced JNK activation (Figure 2a) and effectively protects against SNPinduced cell death in MEF cells (Figure 2b), suggesting the critical role of JNK in RNS-mediated cell death.

Three JNK isoforms have been reported: the ubiquitously expressed JNK1 and JNK2 and the neuronal-specific JNK3. ${ }^{5}$ To further understand the importance of JNK in RNS-induced cell death, we utilized the jnk1-/- MEF. As shown in Figure 2c and d, jnk1-/- MEF are rather resistant to cell death induced by three different RNS donors. More importantly, JNK1 protein reconstitution by stable expression of ectopic JNK1 in the jnk1-I- MEF (Figure 3a) effectively restored the susceptibility of jnk1-I- cells to SNP-induced cell death (Figure $3 \mathrm{~b}$ and c). In addition, we also tested the jnk2-/- MEF and found out that jnk2-I-MEF responded to RNS treatment similarly as WT MEF (data not shown). Therefore, JNK1, but not JNK2, appears to play an important role in determining susceptibility of MEF to RNS-induced caspase-independent non-apoptotic cell death.

TRAF2 is required for RNS-induced JNK activation and cell death. After establishing the role of JNK1 in RNSinduced cell death, here we attempted to elucidate the signaling pathway controlling RNS-induced JNK activation. TRAF2 is one of the key signaling molecules upstream of JNK, especially in the TNF receptor 1 (TNFR1) pathway. ${ }^{11}$ We have reported previously that TRAF2 plays an important role in reactive oxygen species (ROS)-induced JNK 

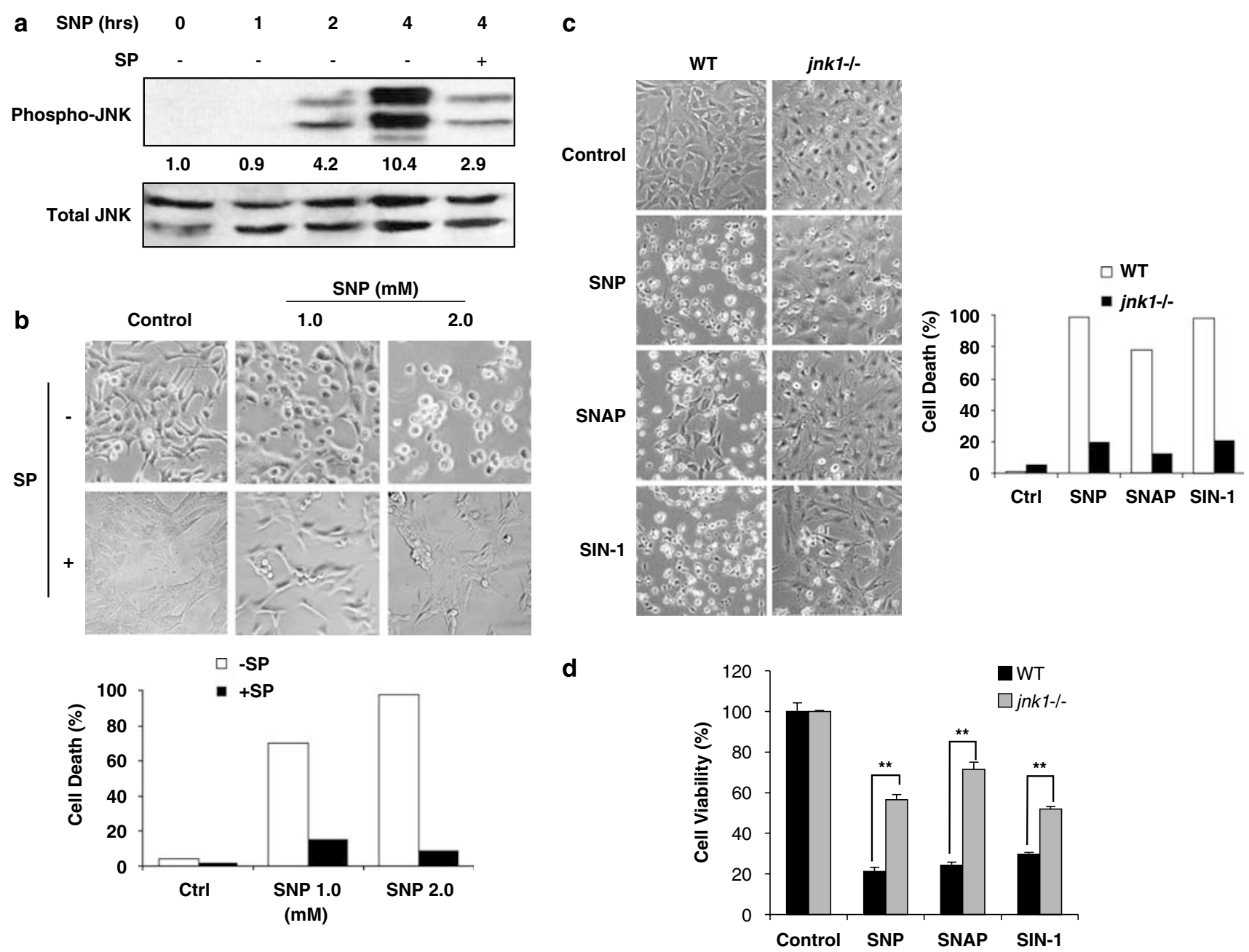

Figure 2 JNK is required for RNS-induced cell death. (a) SNP induces JNK activation. WT MEF cells were treated with SNP (1 mM) for designated time with/without $1 \mathrm{~h}$ pretreatment of JNK inhibitor SP $(20 \mu \mathrm{M})$ and the phospho- and total JNK were detected by Western blotting. (b) JNK inhibitor protects WT MEF from SNP-induced cell death. WT MEF cells were treated with SNP (up to $2 \mathrm{mM}$ ) for $12 \mathrm{~h}$ with/without SP pretreatment $(20 \mu \mathrm{M} \times 1 \mathrm{~h}$ ). Representative images were taken by a phase-contrast microscopy showing the morphological changes of the cell ( $\times 200)$. Quantification of cell death according to the numbers of rounded cells was shown in the lower panel. (c) jnk1-I - MEF are resistant to RNS donors-induced cell death. WT and jnk1-I- MEF cells were treated with SNP, SNAP and SIN-1 (at $2 \mathrm{mM}$ ), respectively, for $12 \mathrm{~h}$. Representative images were taken by a phase-contrast microscopy $(\times 200)$. Quantification of cell death according to the numbers of rounded cells was shown in the right side panel. (d) MEF deficient of JNK1 are resistant to RNS donors-induced cell death. WT and jnk1-I- MEF cells were treated as described in (c), and the relative cell viability was measured using MTT test and the data were presented as mean \pm S.D. from three independent experiments $\left({ }^{\star \star} P<0.01, t\right.$-test)

activation and necrotic cell death. ${ }^{12}$ Here we utilized the traf2-/- MEF to test the relevance of TRAF2 in RNSmediated JNK activation and cell death. As shown in Figure $4 \mathrm{a}$ and $\mathrm{d}$, the traf2-I- cells are almost completely resistant to cell death induced by SNP, SNAP and SIN-1 (Figure 4a and d). In contrast, the MEF deficient of receptor interacting protein 1 (RIP1) were found to respond to RNS treatment similarly to WT MEF (data not shown). Such a finding is indeed contradictory to the effect of ROS in which both RIP and TRAF2 were required for JNK activation and cell death. ${ }^{12}$ Strikingly, RNS-induced JNK activation was completely abolished in the traf2-/- MEF (Figure 4e), implying that (i) TRAF2 is required for RNS-mediated JNK activation and (ii) resistance of traf2-/- MEF to RNS is due to lack of JNK activation. To further strengthen our arguments, we reconstituted TRAF2 protein into traf2-/cells via stable transfection (Figure $4 b$ ). The reconstitution of
TRAF2 protein completely restored the sensitivity of traf2-/MEF to SNP-induced JNK activation (Figure 4e) and cell death (Figure $4 \mathrm{c}$ and $\mathrm{d}$ ). All these observations clearly suggest that TRAF2 is a critical regulator controlling the RNS-induced JNK activation and cell death.

ASK1 is an important mediator between TRAF2 and JNK in RNS-induced cell death. In the TNFR signaling pathway, ASK1 serves as an important signaling proteinmediating JNK activation downstream of TRAF2. ${ }^{13}$ Role of ASK1 has also been well established for oxidative stressinduced JNK activation. ${ }^{14}$ On the other hand, there are conflicting reports on whether RNS activate or inhibit ASK1. ${ }^{7,15}$ Here we explored the involvement of ASK1 in RNS-induced JNK activation and cell death. In WT MEF, SNP induced rapid and transient ASK1 activation (Figure 5A), preceding RNS-induced JNK activation 

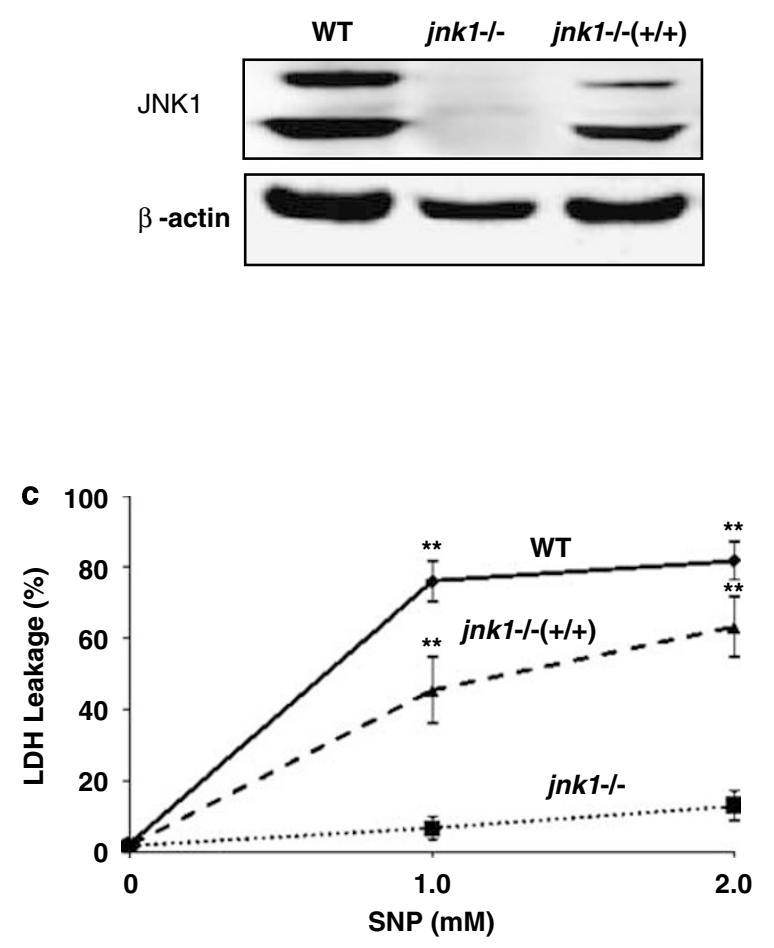

b
WT
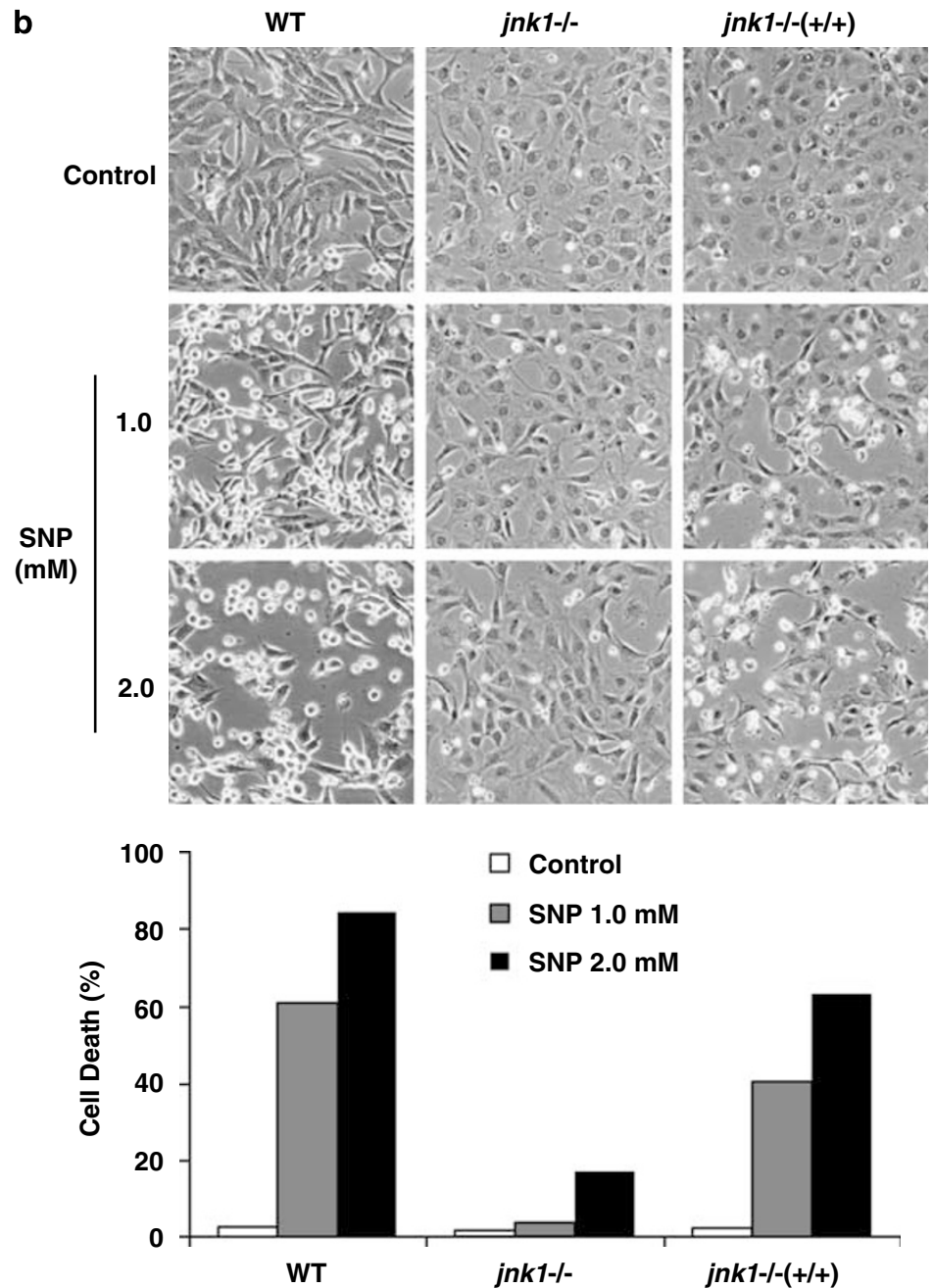

$\square$ Control

$\square$ SNP $1.0 \mathrm{mM}$

SNP $2.0 \mathrm{mM}$
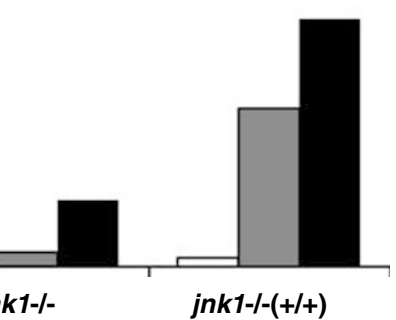

Figure 3 JNK1 reconstitution restores the susceptibility of jnk1-I- cells to RNS-induced cell death. (a) Validation of JNK1 gene knockout and stable reconstitution by Western blot. (b) Stable reconstitution of JNK1 protein restored the susceptibility to RNS-induced cell death. Cells were treated with SNP (up to $2 \mathrm{mM}$ ) for $12 \mathrm{~h}$ and the morphological changes were recorded using a phase-contrast microscope $(\times 200)$. Quantification of cell death according to the numbers of rounded cells was shown in the lower panel. (c) Quantification of SNP dose-dependent cell death of WT, jnk1-I- and jnk1-I- + I+ MEF cells by LDH leakage assay. ( ${ }^{* *} P<0.01, t$-test, comparing with the control group)

(Figure 2a). Notably, in traf2-/- cells, SNP failed to induce any ASK1 activation (Figure 5A), consistent with the absence of JNK activation observed earlier (Figure 4e). Moreover, stable reconstitution of TRAF2 in traf2-/- cells almost completely restored ASK1 activation (Figure 5A). The high background of both ASK1 and JNK activation in the TRAF2reconstituted cells (Figures $4 e$ and $5 \mathrm{~A}$ ) is likely due to the higher level of ectopically expressed TRAF2 protein (Figure 4b). All these observations collectively support the notion that RNS-induced JNK activation is achieved through TRAF2 and ASK1.

To further elucidate the importance of ASK1 in RNSinduced cell death, we transiently transfected WT MEF cells with a dominant-negative ask1 (ask1 without the functional coiled-coil domain (pcDNA-ask1 1 coil)), ${ }^{16}$ together with a GFP expression vector as the transfection marker (green fluorescence indicating successful transfection). Based on the morphological changes, it is clear that cells with successful transfection of ask $1 \Delta$ coil plasmid were found to be resistant to SNP-induced cell death in comparison to those with successful transfection of empty pcDNA vector (Figure $5 B$ ), suggesting that RNS-induced cell death requires a functional ASK1.

RNS engage membrane lipid rafts for JNK activation and cell death. Lipid rafts are membrane microdomains enriched of glycosphingolipid and cholesterol in which lipid acyl chains are tightly packed and highly extended. ${ }^{17}$ Lipid rafts have been proven to be important in many signaling pathways triggered by various inducers. ${ }^{18}$ In our attempt to elucidate the signaling events upstream of TRAF2 in RNSinduced JNK activation and cell death, we explored the possible involvement of membrane lipid rafts. First, it was found that pretreatment with methyl- $\beta$-cyclodextrin $(M \beta C D)$, a known lipid raft structure disruptor by depleting cholesterol, ${ }^{17,19}$ significantly protected cells from death induced by SNP (Figure $6 a$ and b). Next, M $\beta C D$ pretreatment almost completely blocked RNS-induced JNK 
a

TRAF2 - -
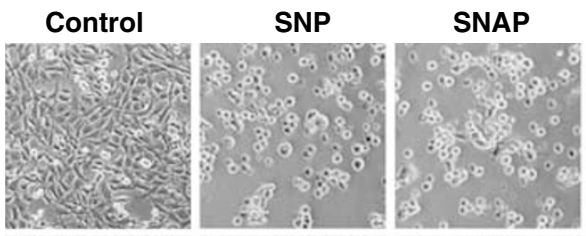

SIN-1
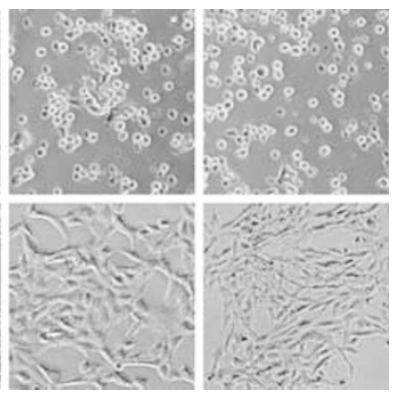

WT

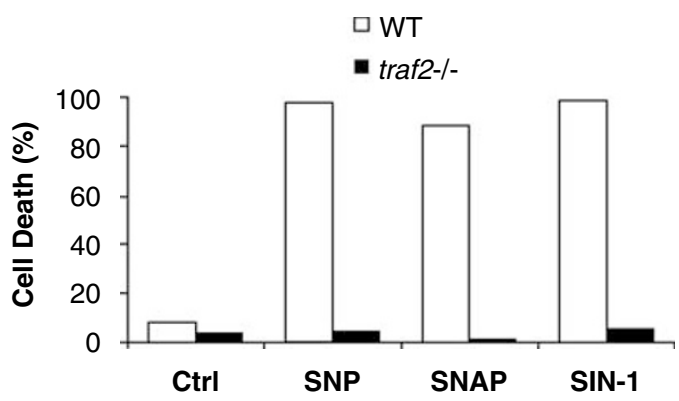

b

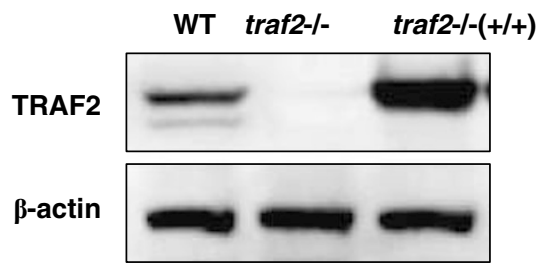

c

Control
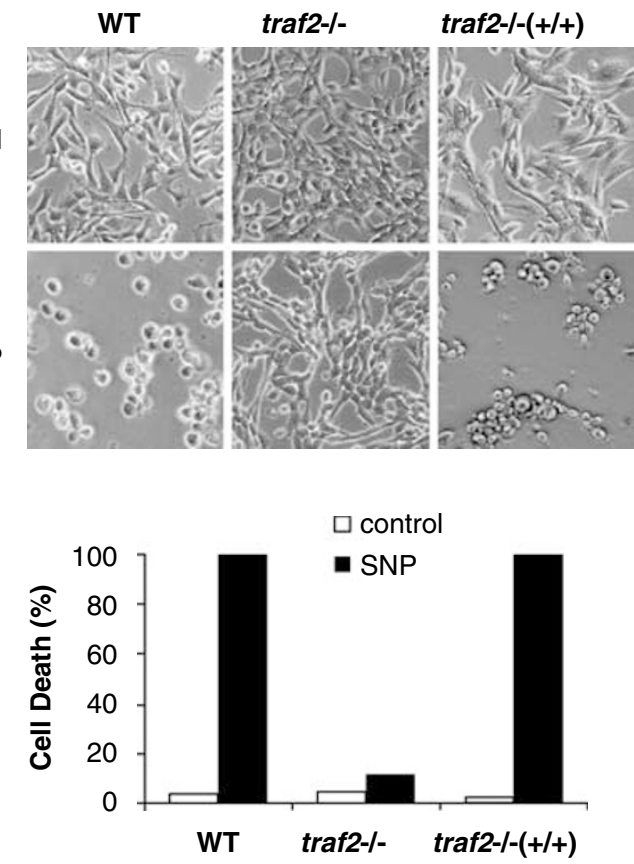

d

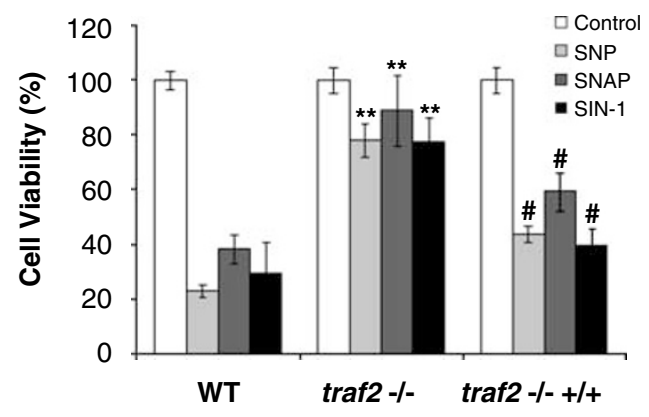

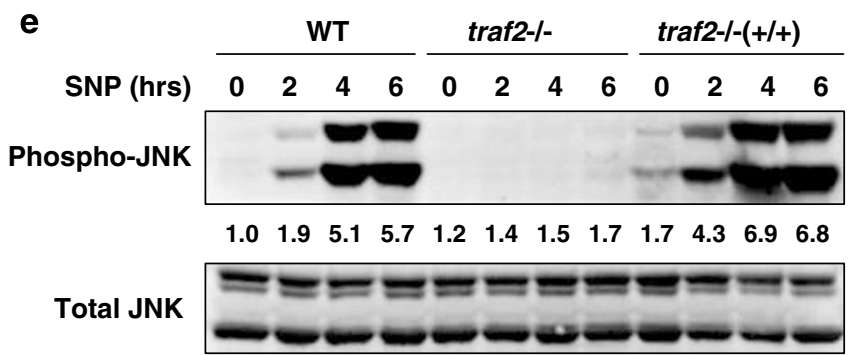

Figure 4 TRAF2 is an essential upstream regulator in RNS-induced JNK activation and cell death. (a) TRAF2 knockout MEF (traf2-/-) are resistant to RNS-induced cell death. WT and traf2-I- MEF cells were treated with SNP, SNAP and SIN-1 (at $1 \mathrm{mM}$ ), respectively, for $12 \mathrm{~h}$. Representative images of cell morphological changes were taken by a phase-contrast microscope $(\times 200)$. Quantification of cell death according to the numbers of rounded cells was shown in the lower panel. (b) Validation of TRAF2 gene knockout and TRAF2 protein reconstitution in traf2 $-I-$ and traf2 $-I-(+I+)$ MEF cells by Western blot. (c) Stable reconstitution of TRAF2 protein sensitizes traf2-Icells to RNS-induced cell death. Representative images $(\times 200)$ were taken for the morphological changes after cells were treated with SNP $(1 \mathrm{mM} \times 12 \mathrm{~h})$. Quantification of cell death according to the numbers of rounded cells was shown in the lower panel. (d) TRAF2 is required for RNS-induced cell death. WT, traf2 $-I-$ and traf2 $-I-(+I+)$ MEF were treated with SNP, SNAP or SIN-1 (at $1 \mathrm{mM}$ ) for $12 \mathrm{~h}$, the cell viability was determined by MTT test and the data were presented as mean \pm S.D. from three independent experiments $\left({ }^{* *} P<0.01\right.$, $t$-test, comparing with the WT cells with the same treatments, ${ }^{\#} P<0.05$, $t$-test, comparing with the traf2-l-cells with the same treatments). (e) TRAF2 is essential for SNP-induced JNK activation. After treatment with SNP (1.0 mM) for the designated time, cells were collected and lysed in M2 buffer and the proteins were subjected to immunoblotting using both the phospho-JNK and total JNK antibodies

activation (Figure 6c). In contrast, $\mathrm{M} \beta \mathrm{CD}$ even markedly enhanced 12-O-tetradecanoylphorbol 13-acetate (TPA)induced JNK activation (Figure 6c). It is known that TPA activates $\mathrm{JNK}$ mainly through protein kinase $\mathrm{C}$ independent of lipid rafts. ${ }^{20}$ Although it is not known how $M \beta C D$ augmented TPA-induced JNK activation, data from this part of our study clearly suggest that the inhibitory effect of $M \beta C D$ on RNS-induced JNK activation and cell death is achieved through a specific mechanism, most probably via the disruption of the membrane lipid rafts. Such observations 
A

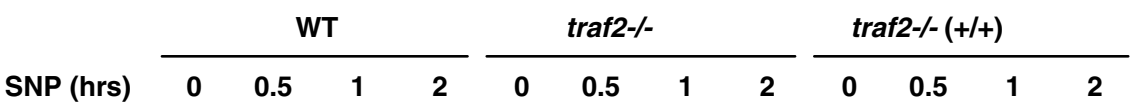
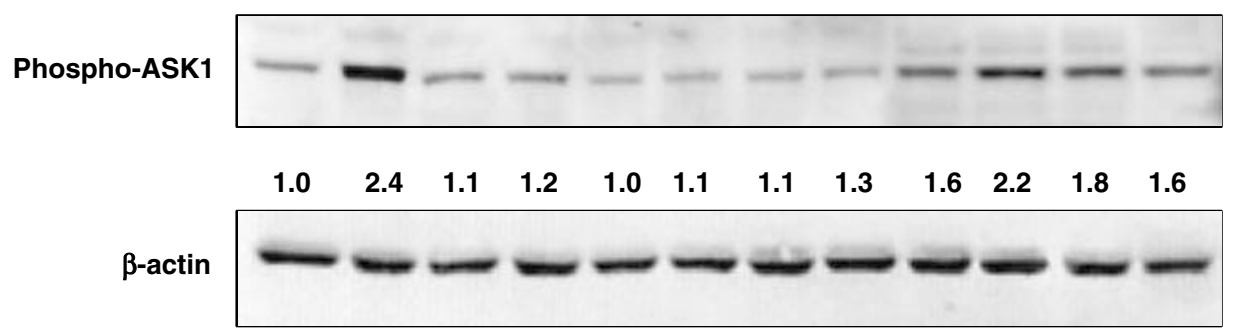

B
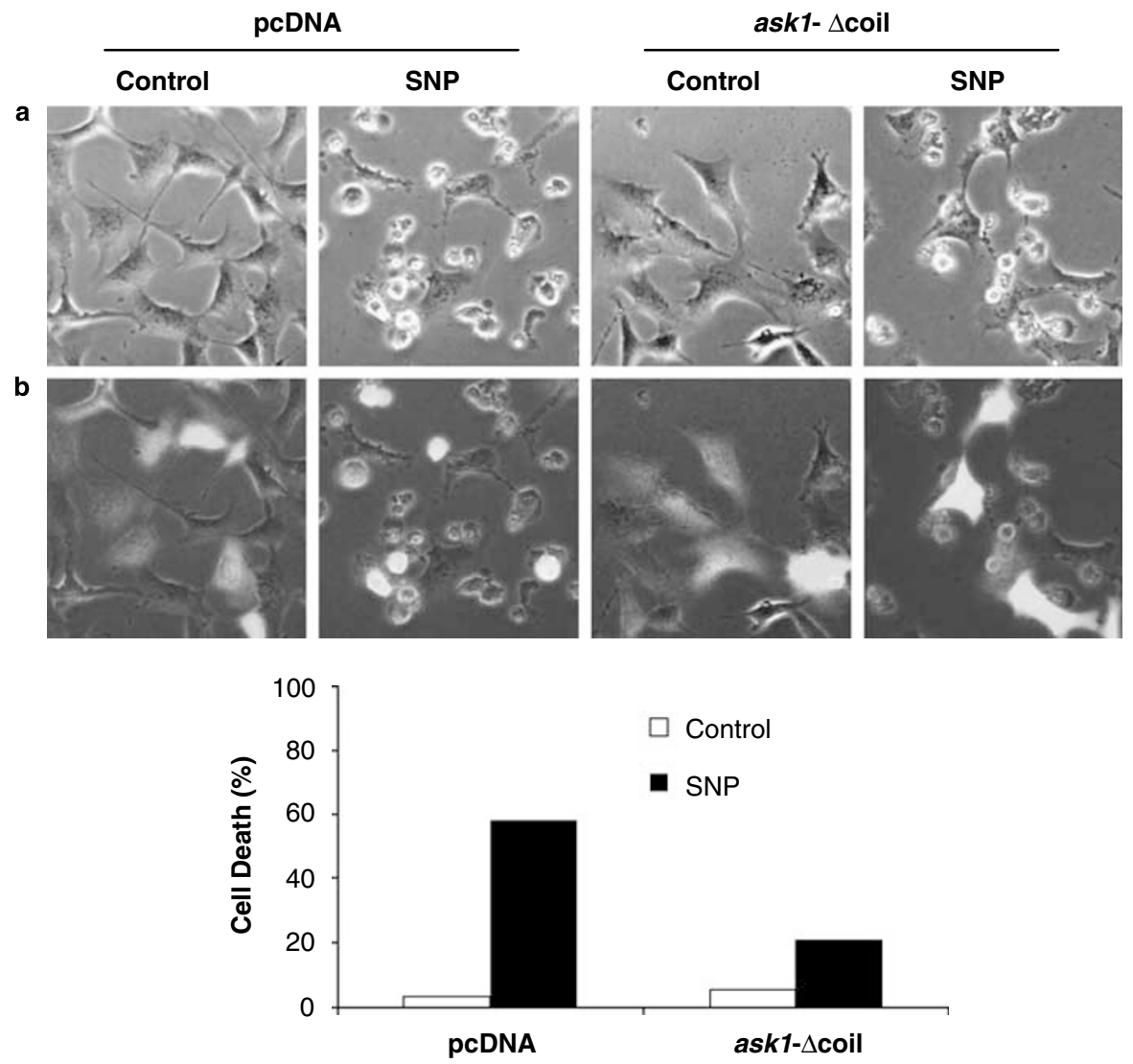

Figure 5 ASK1 plays a critical role downstream of TRAF2 in RNS-induced JNK activation and cell death. (A) TRAF2 is required for SNP-induced ASK1 activation. WT, traf2-1- and traf2-1- $(+1+)$ cells were treated with SNP $(1 \mathrm{mM})$ for designated times and subjected to Western blot for phospho-ASK1. (B) Overexpression of mutant ASK1 suppresses SNP-induced cell death. WT MEF were transiently transfected with pcDNA3.1 or pcDNA-ASK1 $\Delta$ coil, together with pMaxFP ${ }^{\text {TM }}$-Green vector as the transfection marker (cells with green fluorescence were considered as with successful transfection). Cells were treated with SNP (1 mM) for $12 \mathrm{~h}, 24 \mathrm{~h}$ after transfection. Representative images of cell morphological changes were taken by a phase-contrast and fluorescent microscope $(\times 400)(a)$ phase-contrast; (b) merged. Quantification of cell death was shown in the lower panel according to the percentage of rounded cells in a total of 100 cells with green fluorescence

also help us to rule out the possibility that $\mathrm{M} \beta \mathrm{CD}$ directly reacts and inhibits JNK activation.

To further understand the role of lipid raft microdomains in our system, we investigated the localizations of TRAF2 and JNK within the soluble and insoluble fractions prepared by nonionic detergent which respectively represent the cytoplasmic and cytoskeleton/membrane (including lipid rafts) fractions. ${ }^{21,22}$ The purity of these two fractions was confirmed by RIP1 and caveolin, the marker proteins for cytoplasmic and lipid raft fractions. ${ }^{22}$ As shown in Figure 6d, TRAF2 and JNK are all localized in soluble fractions in the control cells. With
SNP treatment, there is a time-dependent translocation of both TRAF2 and JNK to the insoluble fractions: TRAF2 translocation starts earlier (at $15 \mathrm{~min}$ ), but less evident, followed by more significant JNK translocation (at $30 \mathrm{~min}$ ). Since evident JNK activation in RNS-treated cells was found from $2 \mathrm{~h}$ onward (Figures $2 \mathrm{a}$ and $4 \mathrm{e}$ ), it is thus clear that TRAF2 and JNK translocation precedes JNK activation. Moreover, pretreating cells with $\mathrm{M} \beta \mathrm{CD}$ almost totally blocked TRAF2 and JNK translocation induced by SNP (Figure 6e), thus suggesting that the membrane lipid raft structure plays a critical role in recruiting some of the key signaling molecules 
such as TRAF2, which then provides an optimal environment for JNK activation and subsequently cell death.

\section{Discussion}

JNK is the key member of the MAPK family and plays critical roles in regulating cellular responses to various stressors, including the cell death process. ${ }^{5,23,24}$ In this study, we provide evidence demonstrating the critical role of JNK activation in RNS-induced non-apoptotic cell death. Such a finding is indeed consistent with some recent observations that JNK is an effector molecule in non-apoptotic or necrotic cell death mediated by a number of other stimuli such as ROS and $\mathrm{TNF}_{\alpha}{ }^{12,14,25}$ On the other hand, there is evidence, suggesting the role of JNK in RNS-induced apoptotic cell death. For instance, either exogenously administered or endogenously produced RNS were capable of activating JNK and inducing apoptosis in various cell types. ${ }^{26}$ Therefore, data from our study expand the functional scope of JNK in response to RNS and it is likely that JNK is involved in both types of cell death elicited by RNS.

The effect of RNS on JNK has been found to be doubleedged: RNS may activate or inhibit JNK depending on the exposure condition and cell type. The inhibitory effect of RNS on JNK is based on their direct modification of JNK protein by means of S-nitrosylation. ${ }^{27}$ For example, Park et al. ${ }^{28}$ have identified cysteine 116 as the site of such reaction in JNK1. RNS may also inhibit ASK1 activity via a similar mechanism, leading to inhibition of JNK activation. ${ }^{15}$ On the other hand, RNS activate JNK via the typical MAPK activation pathway involving the MAPK kinase kinase (MAPKKK) and MAPK kinase (MAPKK) as upstream kinases. Two MAPKKK (MEKK1 and ASK1) and one MAPKK (MKK4) have been implicated in RNS-induced JNK activation. ${ }^{7,29,30}$ However, little is known about the signaling mechanism upstream of MAPKKK in RNS-mediated JNK activation. In this study, we provide unequivocal evidence showing the critical role of TRAF2 upstream of ASK1 in RNS-mediated JNK activation.

TRAF2 is a key signaling molecule in TNF-mediated JNK activation ${ }^{11,31}$ and TRAF2 is known to interact directly with ASK1 to activate JNK. ${ }^{13,32}$ Moreover, TRAF2 has been shown to be involved in ROS-induced JNK activation and cell death. ${ }^{12,14}$ In this study, we demonstrate, for the first time, that TRAF2 is required for RNS-induced JNK activation and non-apoptotic cell death, based on the following observations: (i) RNS failed to induce JNK activation and cell death in traf2-I- MEF (Figure 4a, d and e) and (ii) TRAF2 reconstitution restored both responses (Figure $4 \mathrm{c}-\mathrm{e}$ ). As discussed above, ASK1 has been shown to be involved in RNS-induced JNK activation and apoptosis. ${ }^{7}$ Recently, ASK1 has also been reported to be involved in regulation of $\mathrm{ROS}$-induced necrotic cell death. ${ }^{33}$ For instance, in cells treated with $\mathrm{H}_{2} \mathrm{O}_{2}$, the recruitment of TRAF2 to ASK1 to form a signalosome is a critical step in $\mathrm{H}_{2} \mathrm{O}_{2}$-induced cell death. ${ }^{14}$ In the present study, RNS fail to activate ASK1 in traf2- - - cells (Figure $5 \mathrm{~A}$ ) and overexpression of a dominant-negative form of ASK1 protects WT MEF from RNS-induced cell death (Figure 5B). Although the direct interaction between TRAF2 and ASK1 was not measured in this study, these observations strongly suggest that ASK1 is an important molecule relaying the cell death signal of RNS from TRAF2 to JNK. Downstream of ASK1, MKK4 or MKK7 is the two main MAPKKs for JNK activation. ${ }^{5}$ Although we were unable to determine RNS-induced MKK4/7 activation due to the lack of suitable antibodies, overexpression of a mutant form MKK7-JNK1 fusion protein protects against RNS-induced cell death (data not shown), suggesting a possible role of MKK7 downstream of ASK1 in RNS-induced JNK activation and cell death.

We next examined the signaling mechanisms upstream of TRAF2 in RNS-induced JNK activation and cell death. Although TRAF2 is one of the key molecules in TNFR1 signaling pathway, ${ }^{11,31}$ it appears that RNS acts on TRAF2 independent of TNFR1, based on our preliminary observation that tnfr1-/- MEF are as susceptible as WT MEF to RNSinduced cell death (data not shown). Lipid rafts, the liquidordered phase microdomains existing within membranes, have been reported involved in various signaling pathways triggered by numbers of stimuli, such as $\mathrm{H}_{2} \mathrm{O}_{2},{ }^{12,34}$ ultraviolet light (UV) ${ }^{35}$ and TNF $\alpha .{ }^{36}$ Data from our study clearly support the notion that RNS promote the recruitment of TRAF2 into lipid rafts and then mediates JNK activation and subsequent cell death. Recruitment of TRAF2 into lipid rafts has been found to be crucial for TNF $\alpha$-induced NF- $\kappa$ B and JNK activation in HT1080 and HeLa cells. ${ }^{22,36}$ However, a recent report showed that lipid rafts are essential for TNF $\alpha$-mediated activation of RhoA but dispensable for the activation of the NF$\kappa \mathrm{B}$ and MAPK pathways in human airway smooth muscle cells, $^{37}$ suggesting that the involvement of lipid rafts and TRAF2 in cell signaling is likely to be cell type specific. An intriguing question to be further studied is the mechanism for recruitment of TRAF2 into lipid rafts. A valuable clue provided by Habelhah et al. ${ }^{22}$ is that the RING domain and zinc finger of TRAF2 is probably essential for its translocation to lipid raft. On the other hand, it is interesting to note that RNS treatment failed to affect RIP1 translocation (Figure 6d). RIP1 is one of the key adaptor molecules in the TNFR1 signaling and works closely with TRAF2 for subsequent signaling events, such as activation of NF- $\kappa$ B and $\mathrm{JNK}^{36,37}$ In this study, it appears that RNS specifically target TRAF2 without engaging RIP1. Such a notion is indeed supported by the fact that rip1-/- cells are as sensitive as WT MEF to RNS-induced cell death (data not shown). Such a selectivity on TRAF2 by RNS is also found to be different from the effect of $\mathrm{H}_{2} \mathrm{O}_{2}$ of which both TRAF2 and RIP1 are required for JNK activation and cell death. ${ }^{12} \mathrm{At}$ present, mechanisms for such specificity remain to be further elucidated. Moreover, it is still not clear how TRAF2 engages the downstream signaling molecules such as ASK1 and MKK4/7 at the site of lipid rafts.

Another important finding of this study is the evident JNK translocation to the insoluble fraction, following TRAF2 translocation temporally (Figure 6d). Such observations are consistent with recent findings that translocation of JNK toward lipid raft microdomains occurred when U937 cell was treated with UV-C. ${ }^{35}$ In addition, redistribution of MAP kinases, including extracellular signal-regulated kinase and p38, to lipid raft structures in stimulated neutrophils has also been reported, ${ }^{38}$ suggesting that membrane lipid rafts may play a role in action of the MAPK family, depending on the study context, such as cell type and the nature of the stimulus. 
a SNP (mM)
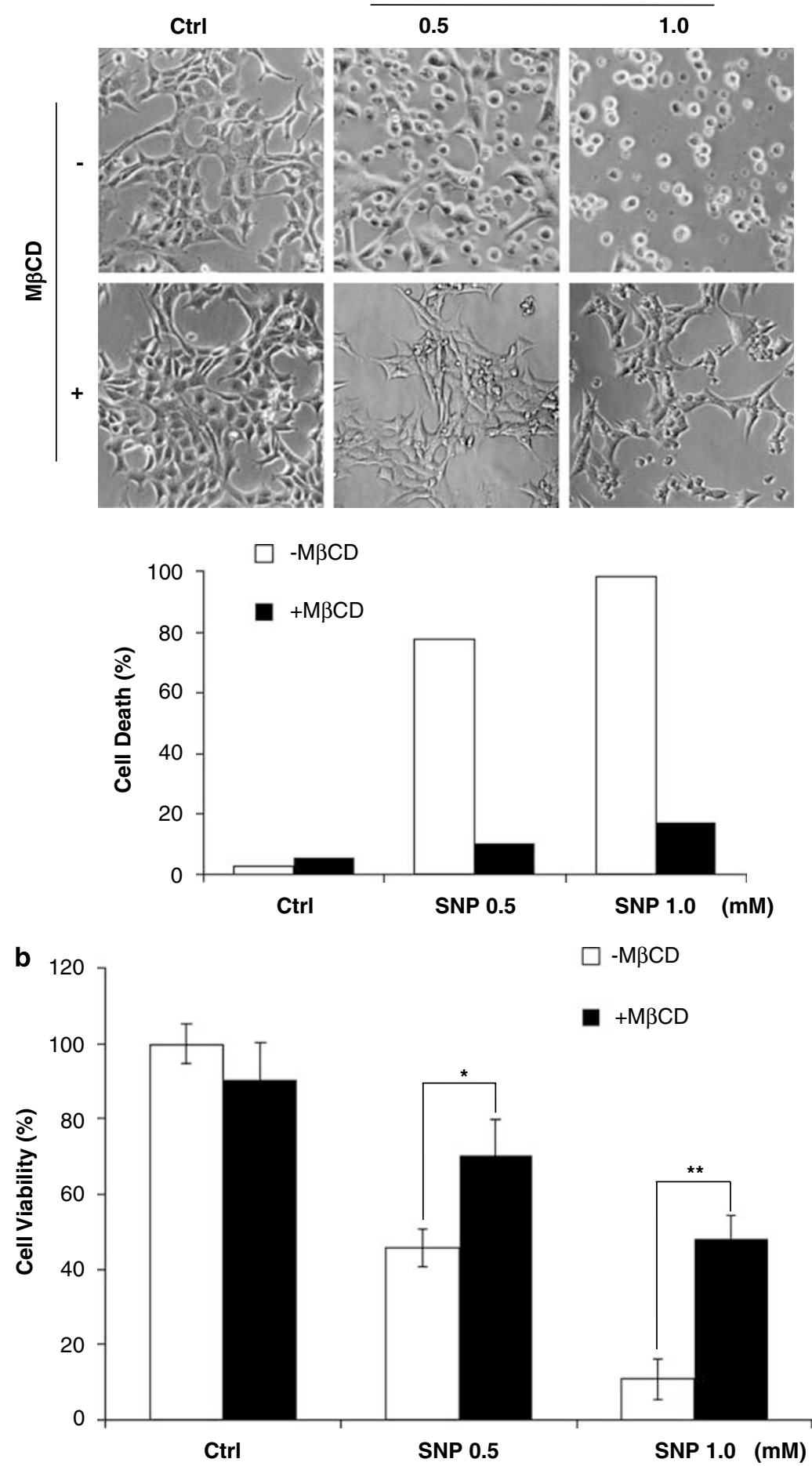

Figure 6 Lipid raft structure is critical for RNS-mediated JNK activation and cell death in MEF cells. (a) M $\beta C D$ protects against SNP-induced cell death. WT MEF cells were pretreated with $\mathrm{M} \beta \mathrm{CD}(2 \mathrm{mM})$ for $30 \mathrm{~min}$, followed by designated SNP treatments for $12 \mathrm{~h}$. Representative images of cell morphological changes were taken by a phasecontrast microscope $(\times 200)$. Quantification of cell death according to the numbers of rounded cells was shown in the lower panel. (b) Quantification of cell viability upon SNP treatment with/without pretreatment of $\mathrm{M} \beta \mathrm{CD}$ by MTT test. WT cells were treated as described in (a), and the data were presented as mean \pm S.D. from three independent experiments ( ${ }^{*} P<0.05,{ }^{*} P<0.01$, $t$-test). (c) M $\beta C D$ blocks the phosphorylation of JNK. WT MEF cells were pretreated with M $\beta C D(2 \mathrm{mM})$ for $30 \mathrm{~min}$, followed with SNP $(1.0 \mathrm{mM} \times 3 \mathrm{~h})$ and TPA $(80 \mathrm{nM} \times 1 \mathrm{~h})$, respectively. (d) TRAF2 and JNK translocation. WT MEF cells were treated with SNP (1.0 mM) for designated time and cell fractionation was performed as described in Materials and Methods. Phospho-JNK, total-JNK and TRAF2 were analyzed by Western blot. RIP and caveolin-1 were used as markers for the cytoplasmic and raft fractions, respectively. (e) M $\beta C D$ blocks the translocations of JNK and TRAF2. WT MEF cells were pretreated with M $\beta C D(2.0 \mathrm{mM})$ for $30 \mathrm{~min}$, followed by SNP $(1.0 \mathrm{mM})$ treatments for $2 \mathrm{~h}$. The insoluble fraction was subjected to immunoblotting as described in (d) 


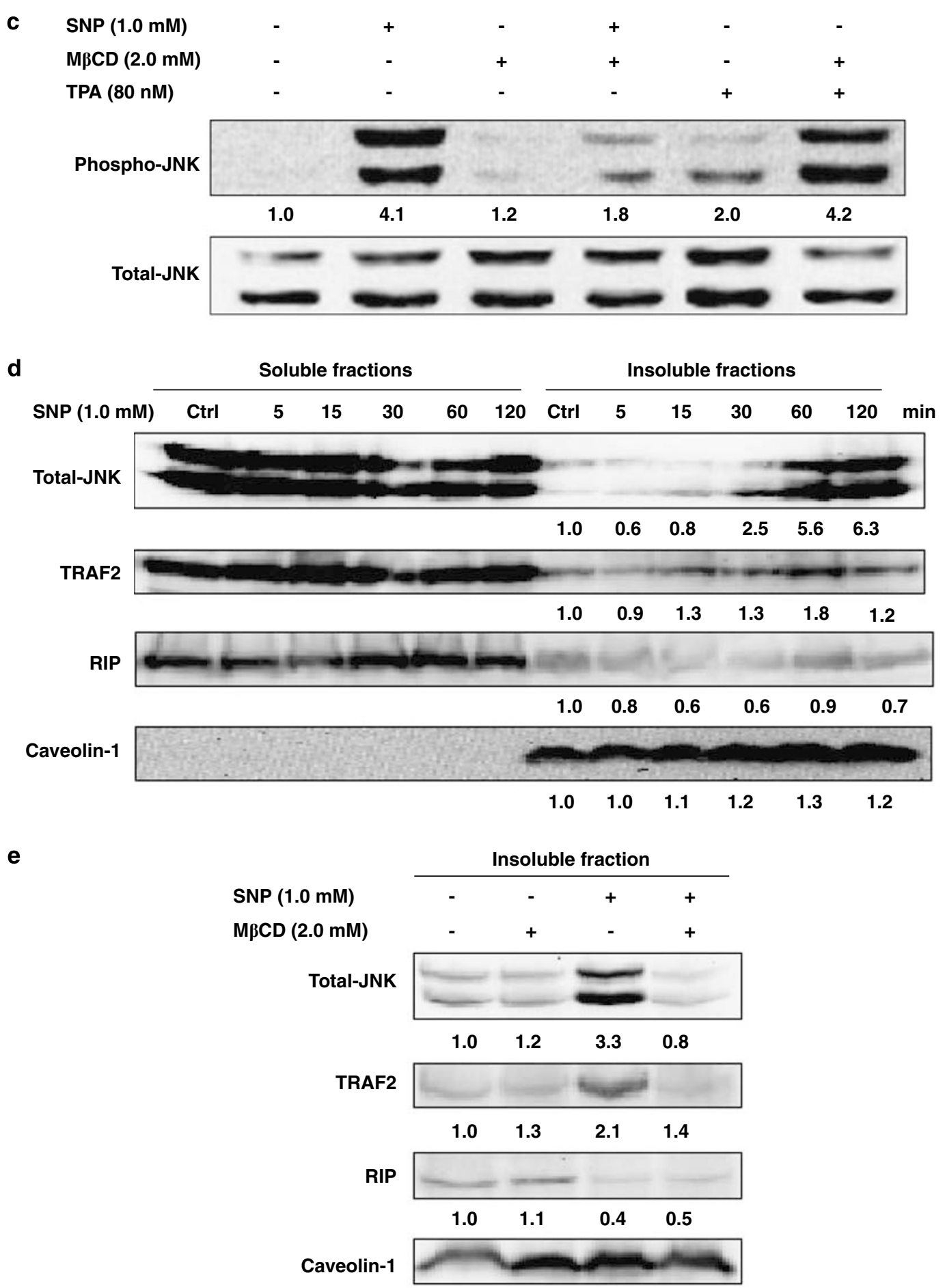

Figure 6 Continued.

Apoptosis and non-apoptotic cell death/necrosis are two distinct forms of cell death and both are closely implicated in the pathological processes of human diseases. ${ }^{39}$ Recent accumulating evidence has given rise to the idea that nonapoptotic or necrotic cell death is executed via defined machinery without the caspase activation and typical apoptotic morphological features. ${ }^{40,41}$ In this work, RNS are found to induce caspase-independent non-apoptotic cell death via a signaling pathway involving lipid raft, TRAF2-ASK1-JNK cascade. Knowledge of such a novel signaling pathway by RNS certainly helps to understand the pathological role of RNS and nitrosative stress in human diseases.

Materials and Methods

Reagents and antibodies. RNS donors (SNP, SIN-1 and SNAP) and JNK inhibitor (SP) were purchased from Calbiochem (San Diego, CA, USA). 
Pan-caspase inhibitor Z-VAD-FMK was purchased from BioMol (Plymouth meeting, PA, USA). Hoechst 33342 and Sytox were purchased from Invitrogen (Molecular Probes, Eugene, OR, USA). Anti-phospho-JNK $\left(\mathrm{Thr}^{183} / \mathrm{Tyr}^{185}\right.$ ) and anti-caspase3 antibodies were from Cell Signaling (Beverly, MA, USA). Anti-TRAF2 antibody was purchased from Santa Cruz (Santa Cruz, CA, USA); anti-JNK1 (clone G151-333), anti-JNK (clone G151-666), anti-caveolin, anti-PARP and anti-RIP antibodies were purchased from BD Pharmingen (San Diego, CA, USA). M $\beta C D$, anti- $\beta$-actin antibodies were purchased from Sigma-Aldrich (St Louis, MO, USA). Anti-phosphoASK-1 antibody has been described previously. ${ }^{16}$

Cell culture and treatments. MEF cells were maintained in Dulbecco's modified Eagle's medium (Sigma) containing 10\% fetal bovine serum (FBS) (HyClone) and $1 \%$ penicillin-streptomycin (Invitrogen) in a $5 \% \mathrm{CO}_{2}$ atmosphere at $37^{\circ} \mathrm{C}$. SNP (dissolved in FBS-free medium), SIN-1 (dissolved in pH 5.0 sodium phosphate buffer) and SNAP (dissolved in DMSO) were prepared as stock solution $(500 \mathrm{mM})$ immediately before treatment.

Detection of cell death. Cell death induced by RNS donors was quantified by using the following three methods: (i) 3-[4,5-dimethylthiazol-2-yl]-2,5-diphenyltetrazolium bromide (MTT) test as described previously and the results were presented as the relative cell viability comparing to the control group; ${ }^{42}$ (ii) lactate dehydrogenase (LDH) leakage quantification test to examine the plasma membrane permeability, by using the cytotoxicity detection kit (Roche) or (iii) cell morphological changes, and the percentage of rounded cells counted among 200 randomly selected cells and the quantification data were presented side by side with the morphological images. For Sytox-Hoechst staining of cell, treated cells were stained with Sytox (50 nM)-Hoechst $(10 \mu \mathrm{g} / \mathrm{ml})$ mixture solution (in PBS) at room temperature for $30 \mathrm{~min}$. The staining of nuclei was visualized and captured under an inverted fluorescent microscope (Nikon ECLIPSE TE2000-S).

Plasmids and transient transfection. pcDNA-ASK1 $\Delta$ coil vector has been described previously. ${ }^{16}$ pcDNA3.1 vector was from Invitrogen (Carlsbad, CA, USA). pMaxFP ${ }^{\mathrm{TM}}$-Green vector was from Amaxa GmbH (Koeln, Germany). The transient transfections were performed using electroporation-based Nucleofector ${ }^{\circledR}$ II device (Program A23) with MEF2 nucleofector kit (Amaxa $\mathrm{GmbH}$, Koeln, Germany). The transfected cells (with green fluorescence) were examined under an inverted fluorescent microscope (Nikon ECLIPSE TE2000-S).

Cell fractionation. Separation of detergent-resistant lipid raft from detergentsoluble fractions was conducted according to previously described with some modifications. ${ }^{22}$ Briefly, cells were washed twice in ice-cold PBS after treatments and were scraped in PBS and spun down at 2000 r.p.m. $4^{\circ} \mathrm{C}$ in a tabletop centrifuge (Eppendorf). The cells were subsequently lysed in TNE $(25 \mathrm{mM}$ Tris $\mathrm{HCl}, \mathrm{pH} 7.4$ $150 \mathrm{mM} \mathrm{NaCl}, 3 \mathrm{mM}$ EDTA and Roche protease inhibitor cocktail), with $1 \%$ Brij 98 at $37^{\circ} \mathrm{C}$ for $30 \mathrm{~min}$. Afterward, the lysates were homogenized by passage through a 23-gauge needle for 10 times on ice, and then were centrifuged at $1000 \mathrm{~g}$ at $4{ }^{\circ} \mathrm{C}$ for $5 \mathrm{~min}$. The postnuclear supernatants were additionally centrifuged at $16000 \mathrm{~g}$ at $4^{\circ} \mathrm{C}$ for $20 \mathrm{~min}$. The supernatants were collected as the soluble fractions. The detergent-insoluble pellets were resuspended and briefly sonicated in the same lysis buffer supplemented with $0.5 \% \mathrm{SDS}$ and $2 \mathrm{mmol} / / \mathrm{DTT}$ and served as the lipid raft fractions.

Western blotting. At the end of designated treatments, cells were lysed in M2 lysis buffer $(20 \mathrm{mM}$ Tris at pH 7, 0.5\% NP-40, $250 \mathrm{mM} \mathrm{NaCl}, 3 \mathrm{mM}$ EDTA, $3 \mathrm{mM}$ EGTA, $2 \mathrm{mM}$ dithiothreitol, $0.5 \mathrm{mM}$ phenylmethylsulfonyl fluoride, $20 \mathrm{mM}$ glycerol phosphate, $1 \mathrm{mM}$ sodium vanadate and proteinase inhibitor cocktail). Equal amount of protein was fractionated on SDS-PAGE and transferred onto PVDF membrane (Bio-Rad). After blocked with $5 \%$ non-fat milk, the membrane was probed with designated first and second antibodies and developed with enhanced chemiluminescence method (Pierce) and visualized by Kodak Image Station 440CF (Kodak). The band density was quantified using ImageJ image processing program developed by $\mathrm{NIH}$ and normalized to that of the control group.

1. Nathan $C$. Specificity of a third kind: reactive oxygen and nitrogen intermediates in cell signaling. J Clin Invest 2003; 111: 769-778.

2. Shen HM, Liu ZG. JNK signaling pathway is a key modulator in cell death mediated by reactive oxygen and nitrogen species. Free Radic Biol Med 2006; 40: 928-939.

3. Tarr JM, Eggleton P, Winyard PG. Nitric oxide and the regulation of apoptosis in tumour cells. Curr Pharm Des 2006; 12: 4445-4468.
4. Cantoni O, Guidarelli A, Palomba L, Fiorani M. U937 cell necrosis mediated by peroxynitrite is not caused by depletion of ATP and is prevented by arachidonate via an ATP-dependent mechanism. Mol Pharmacol 2005; 67: 1399-1405.

5. Davis RJ. Signal transduction by the JNK group of MAP kinases. Cell 2000; 103: 239-252.

6. Yoo K, Choi JW, Choi MS, Ryu MK, Park GH, Jeon MJ et al. Mitogen-activated protein kinases (MAPKs) mediate SIN-1/glucose deprivation-induced death in rat primary astrocytes. Arch Pharm Res 2005; 28: 942-947.

7. Jibiki I, Hashimoto S, Maruoka S, Gon Y, Matsuzawa A, Nishitoh H et al. Apoptosis signalregulating kinase 1-mediated signaling pathway regulates nitric oxide-induced activator protein-1 activation in human bronchial epithelial cells. Am J Respir Crit Care Med 2003 167: 856-861.

8. Sumbayev VV, Yasinska IM. Regulation of MAP kinase-dependent apoptotic pathway: implication of reactive oxygen and nitrogen species. Arch Biochem Biophys 2005; 436 $406-412$.

9. Kyriakis JM, Avruch J. Mammalian mitogen-activated protein kinase signal transduction pathways activated by stress and inflammation. Physiol Rev 2001; 81: 807-869.

10. Levonen AL, Patel RP, Brookes P, Go YM, Jo H, Parthasarathy $S$ et al. Mechanisms of cell signaling by nitric oxide and peroxynitrite: from mitochondria to MAP kinases. Antioxid Redox Signal 2001; 3: 215-229.

11. Chen G, Goeddel DV. TNF-R1 signaling: a beautiful pathway. Science 2002; 296 1634-1635

12. Shen HM, Lin Y, Choksi S, Tran J, Jin T, Chang L et al. Essential roles of receptorinteracting protein and TRAF2 in oxidative stress-induced cell death. Mol Cell Biol 2004 24: 5914-5922.

13. Nishitoh $\mathrm{H}$, Saitoh M, Mochida $Y$, Takeda $K$, Nakano $H$, Rothe $M$ et al. ASK1 is essential for JNK/SAPK activation by TRAF2. Mol Cell 1998; 2: 389-395.

14. Noguchi T, Takeda K, Matsuzawa A, Saegusa K, Nakano H, Gohda J et al. Recruitment of tumor necrosis factor receptor-associated factor family proteins to apoptosis signalregulating kinase 1 signalosome is essential for oxidative stress-induced cell death. J Bio Chem 2005; 280: 37033-37040.

15. Park HS, Yu JW, Cho JH, Kim MS, Huh SH, Ryoo K et al. Inhibition of apoptosis signalregulating kinase 1 by nitric oxide through a thiol redox mechanism. J Biol Chem 2004; 279 7584-7590.

16. Tobiume K, Saitoh M, Ichijo $\mathrm{H}$. Activation of apoptosis signal-regulating kinase 1 by the stress-induced activating phosphorylation of pre-formed oligomer. J Cell Physiol 2002; 191 95-104.

17. Brown DA. Lipid rafts, detergent-resistant membranes, and raft targeting signals Physiology (Bethesda) 2006; 21: 430-439.

18. Jacobson K, Mouritsen OG, Anderson RG. Lipid rafts: at a crossroad between cell biology and physics. Nat Cell Biol 2007; 9: 7-14.

19. Calzolari A, Raggi C, Deaglio S, Sposi NM, Stafsnes M, Fecchi K et al. TfR2 localizes in lipid raft domains and is released in exosomes to activate signal transduction along the MAPK pathway. J Cell Sci 2006; 119: 4486-4498.

20. Lopez-Bergami P, Habelhah H, Bhoumik A, Zhang W, Wang LH, Ronai Z. RACK1 mediates activation of JNK by protein kinase C (corrected). Mol Cell 2005; 19 309-320.

21. Huang $Q$, Shen HM, Shui G, Wenk MR, Ong CN. Emodin inhibits tumor cell adhesion through disruption of the membrane lipid Raft-associated integrin signaling pathway. Cancer Res 2006; 66: 5807-5815.

22. Habelhah H, Takahashi S, Cho SG, Kadoya T, Watanabe T, Ronai Z. Ubiquitination and translocation of TRAF2 is required for activation of JNK but not of p38 or NF-kappaB. EMBO J 2004; 23: 322-332.

23. Lin A. Activation of the JNK signaling pathway: breaking the brake on apoptosis. Bioessays 2003; 25: 17-24.

24. Karin M, Gallagher E. From JNK to pay dirt: jun kinases, their biochemistry, physiology and clinical importance. IUBMB Life 2005; 57: 283-295

25. Zhang S, Lin Y, Kim YS, Hande MP, Liu ZG, Shen HM. c-Jun N-terminal kinase mediates hydrogen peroxide-induced cell death via sustained poly(ADP-ribose) polymerase-1 activation. Cell Death Differ 2007; 14: 1001-1010.

26. Shacka JJ, Sahawneh MA, Gonzalez JD, Ye YZ, D'Alessandro TL, Estevez AG. Two distinct signaling pathways regulate peroxynitrite-induced apoptosis in $\mathrm{PC} 12$ cells. Cell Death Differ 2006; 13: 1506-1514.

27. Park HS, Mo JS, Choi EJ. Nitric oxide inhibits an interaction between JNK1 and c-Jun through nitrosylation. Biochem Biophys Res Commun 2006; 351: 281-286.

28. Park HS, Huh SH, Kim MS, Lee SH, Choi EJ. Nitric oxide negatively regulates c-Jun Nterminal kinase/stress-activated protein kinase by means of S-nitrosylation. Proc Natl Acad Sci USA 2000; 97: 14382-14387.

29. Andreka P, Zang J, Dougherty C, Slepak TI, Webster KA, Bishopric NH. Cytoprotection by Jun kinase during nitric oxide-induced cardiac myocyte apoptosis. Circ Res 2001; 88: 305-312.

30. Shrivastava P, Pantano C, Watkin R, McElhinney B, Guala A, Poynter ML et al. Reactive nitrogen species-induced cell death requires Fas-dependent activation of c-Jun $\mathrm{N}$-terminal kinase. Mol Cell Biol 2004; 24: 6763-6772.

31. Wajant $H$, Scheurich $P$. Tumor necrosis factor receptor-associated factor (TRAF) 2 and its role in TNF signaling. Int J Biochem Cell Biol 2001; 33: 19-32.

32. Takeda K, Matsuzawa A, Nishitoh $\mathrm{H}$, Ichijo $\mathrm{H}$. Roles of MAPKKK ASK1 in stress-induced cell death. Cell Struct Funct 2003; 28: 23-29. 
33. Nagai $\mathrm{H}$, Noguchi T, Takeda $\mathrm{K}$, Ichijo $\mathrm{H}$. Pathophysiological roles of ASK1-MAP kinase signaling pathways. J Biochem Mol Biol 2007; 40: 1-6.

34. Yang B, Oo TN, Rizzo V. Lipid rafts mediate $\mathrm{H} 2 \mathrm{O} 2$ prosurvival effects in cultured endothelial cells. FASEB J 2006; 20: 1501-1503.

35. Charruyer A, Grazide S, Bezombes C, Muller S, Laurent G, Jaffrezou JP. UV-C light induces raft-associated acid sphingomyelinase and JNK activation and translocation independently on a nuclear signal. J Biol Chem 2005; 280: 19196-19204.

36. Legler DF, Micheau O, Doucey MA, Tschopp J, Bron C. Recruitment of TNF receptor 1 to lipid rafts is essential for TNFalpha-mediated NF-kappaB activation. Immunity 2003; 18: 655-664.

37. Hunter I, Nixon GF. Spatial compartmentalization of tumor necrosis factor (TNF) receptor 1-dependent signaling pathways in human airway smooth muscle cells. Lipid rafts are essential for TNF-alpha-mediated activation of RhoA but dispensable for the activation of the NF-kappaB and MAPK pathways. J Biol Chem 2006; 281: 34705-34715.
38. David A, Fridlich $\mathrm{R}$, Aviram I. The presence of membrane Proteinase 3 in neutrophil lipid rafts and its colocalization with FcgammaRIllb and cytochrome b558. Exp Cell Res 2005; 308: 156-165.

39. Galluzzi L, Maiuri MC, Vitale I, Zischka H, Castedo M, Zitvogel L et al. Cell death modalities: classification and pathophysiological implications. Cell Death Differ 2007; 14: 1237-1243.

40. Golstein P, Kroemer G. Cell death by necrosis: towards a molecular definition. Trends Biochem Sci 2007; 32: 37-43.

41. Shen HM, Pervaiz S. TNF receptor superfamily-induced cell death: redox-dependent execution. FASEB J 2006; 20: 1589-1598.

42. Yang CF, Shen HM, Ong CN. Protective effect of ebselen against hydrogen peroxide-induced cytotoxicity and DNA damage in HepG2 cells. Biochem Pharmacol 1999; 57: 273-279. 